\title{
PALAVRA, CENA E MEDIAÇÃO TECNOLÓGICA: EDIÇÃO ONLINE DE OBRAS DRAMÁTICAS CLÁSSICAS
}

\section{WORD, STAGE AND TECHNOLOGY: ONLINE EDITION OF CLASSICS TEXTS}

Marcus Mota*

RESUMO: Entre 2010 e 2011 foi realizado, no Laboratório de Dramatugia da Universidade de Brasília, o projeto "Tragédia e hipertexto: desenvolvimento de edição online de obras dramáticas clássicas"'. O projeto objetivou a produção de um protótipo de uma interface online que disponibilizaria para o usuário uma organização de dados visuais e sonoros elaborados a partir da textualidade de uma tragédia grega. Tal interface ao fim integra os níveis de referência que uma tragédia grega apresenta a partir do modo como suas palavras são distribuídas em séries métricas e linguísticas. Como forma de subsidiar futuros empreendimentos similares, relato aqui parte da pesquisa e dos seus resultados, bem como as dificuldades encontradas.

PALAVRAS-CHAVE: Hipertexto. Tragédia Grega. Métrica.

ABSTRACT: The research Project "Tragedy and Hypertext: Online edition of Classical Dramas" was developed by Drama Lab at

* Mestre em Teoria da Literatura pela Universidade de Brasília (1992) e doutorado em História pela mesma universidade (2002). Atualmente é professor adjunto da Universidade de Brasília, onde dirige o LADI (Laboratório de Dramaturgia e Imaginação Dramática). E-mail: marcusmotaunb@ gmail.com

1 Projeto financiado pelo CNPq (400970/2010-4). Neste projeto além de mim, trabalharam como pesquisadores e técnicos envolvidos: Gisele Pires de Oliveira, Geraldo Martins, Eufrásio Prates, Constantino Filho, Flávio Café, e Glauco Maciel. 
University of Brasília, Brazil, from 2010 to 2011. This project aimed to produce a prototype of an online interface which would make available sound and visual data based on ancient greek tragedy textuality. When finished, this interface integrates information from linguistic and metrical layers. In order to support future projects, it's reported here methodologies used and results found during the construction of the prototype of the online interface.

KEYWORDS: Hypertext. Greek Tragedy. Metrics. 


\section{PALAVRA, CENA E MEDIAÇÃO TECNOLÓGICA: EDIÇÃO ONLINE DE OBRAS DRAMÁTICAS CLÁSSICAS}

\section{DISCUSSÃO INICIAL (PROJETO 2009-2011)}

O projeto "Tragédia e hipertexto: desenvolvimento de edição online de obras dramáticas clássicas” é desdobramento e ampliação de um projeto anterior, em que procedimentos utilizados no tratamento do texto performativo da tragédia grega foram efetivados e redefinidos, como a escansão e comentário textual ${ }^{1}$. A novidade neste novo projeto é que há uma maior integração entre a escansão, a materialidade linguística e a materialidade sonora dos vocábulos gregos, procedimentos que no projeto anterior ainda se restringiam a gerar dados isoladamente.

Para tornar claro o novo momento deste projeto, retomo algumas informações do projeto anterior. Entre 2009 e 2011, propôs-se o desenvolvimento de uma metodologia de análise e de produção de eventos performativos audiovisualmente orientados. A partir do estudo de alguns documentos da dramaturgia musical da tragédia grega, passou-se ao mapeamento e dis-

1 Referência ao projeto “ Teatro, Música e metro: Simulações Audiovisuais a partir de padrões métricos da Tragédia grega”desenvolvido entre 2009 e 2011 no LADI, também financiado pelo CNPq (400937/2009-3). Sobre o projeto, ver Mota (2011). Neste projeto, além da mesma equipe do projeto anterior, tivemos a significativa participação de Alexandre Rangel no design e desenvolvimento do protótipo da interface. 
cussão de procedimentos empregados e sua representação visual e sonora, por meio de recursos gráficos como tabelas,esquemas e arquivos de áudio.

Como campo interartístico e multidisciplinar, a Dramaturgia Musical engloba uma diversidade de procedimentos e uma longa tradição de realizações estéticas, constituindo-se como desafio às estratégias de inteligibilidade e processos criativos ${ }^{2}$.

Dentro desse campo, temos os textos dos espetáculos da Tragédia Grega, verdadeiros fósseis de eventos multidimensionais, que registram em sua métrica, arranjo das partes faladas e cantadas e rubricas internas experiências sobre os vínculos entre composição, recepção e produção de obras dramático-musicais ${ }^{3}$. Não se trata aqui de reconstruir o contexto original das performances e, sim, de gerar, a partir de uma detida análise (close reading) dessas textualidades, dados que, depois de seu tratamento técnico, são organizados em padrões e conceitos dos atos de se propor um design sonoro da cena. Ainda, não se busca transformar estes dados organizados por padrões e conceitos operatórios, e explicitados por uma metalinguagem e representações visuais e sonoras, em modelo do que devam ser os nexos entre música e teatro. As textualidades interrogadas são contextos e experimentos desses nexos.

Usar textos restantes da tragédia grega para mapear procedimentos de dramaturgia musical é uma atividade presente tanto nas discussões do grupo de pensadores e músicos organizados em torno da Camerata Florentina (1573-1580), que desenvolveu teorias e expressões responsáveis pelas primeiras óperas, ou 'dramas em música', como também nas proposições e obras de Richard Wagner, e o desenvolvimento da idéia de Gesamtkunstwerk, ou 'obra de arte total's. Em ambas as propostas, a apropriação criativa da tradição ateniense de se elaborar obras dramático-musicais se faz por meio da identificação de conceitos operatórios, de um elenco de procedimentos

2 Conf. Blassingha (1983); Cook (2001); Heile (2006); McMillin (2006); ADorno EIsler (2007); Feneyrou (2003).

3 Como se vê nas obras de PIckard-Cambrigdge (1968); Scott, W.C. (1984); Scott,W.C. (1996).

4 Palisca (1989); Carter (2002); Mota e Soares (2001).

5 Wagner (1995); Goldman e Spinchorn (1964); Ewans (1982). 
que são efetivados na composição de eventos multidimensionais, como o recurso ao leitmotiv, ou motivo condutor, que explicita modos de construir a coerência da obra e de sua recepção.

Diante disso, a identificação da organização dramático-musical dos textos restantes da Tragédia grega nos oferece não só um estoque de técnicas como uma argumentação sobre o campo de realizações da Dramaturgia musical. A intricada contextura de distribuição das cenas, de recorrências métrico-temáticas e de rubricas internas singulariza em cada texto restante possibilidades de combinações de procedimentos e nexos recepcionais ${ }^{6}$ . Não se trata de explicar obras individuais, de parafrasear seu sentido. A textualidade das obras dramático-musicais atenienses é um código que, decifrado, revela modos de enfrentamento das relações entre teatro e música.

Tais textos foram realizados dentro de uma cultura performativa - Mousikê - caracterizada pela transmissão de conhecimentos em situação de contato interindividual em cantos, danças e desempenhos sonoramente orientados. Nos últimos anos tal cultura tem sido submetida a uma exegese mais competente, produzindo uma verdadeira revolução epistemológica nos Estudos Clássicos?.

Tal revolução epistemológica só se deu em virtude da modificação dos pressupostos aplicados ao estudo da tradição clássica. É o impacto do conceito de "performance" sobre tal tradição que tem revigorado a leitura e análise dos 'monumentos do passado's. O produtivo encontro acadêmico entre Estudos Clássicos e Estudos da Performance dinamiza o diálogo entre tradição e contemporaneidade, enfatizando condições materiais, a materialidade das trocas interculturais, históricas e estéticas.

Diante disso, o ato de se problematizar tragédias gregas como obras audiovisuais deixa de ser uma atividade museológica, 'medusante. Como artefatos de uma 'Sociedade de Espetáculo', os intrincados padrões performativos presentes nestes textos restantes da Mousikê nos proporcionam dados para um maior esclarecimento desse campo interartístico e multitarefa do design sonoro ${ }^{9}$.

6 Sharon (1994); West (1987).

7 Gentili (1988); Murray, P. e Wilson, P. (2004).

8 Nagy (1996); Nagy (1990); Wiles (2000); Wiles (1997).

9 Leonard (2001); Bracewell (1993); Lebrecht \& Kaye (1999). 
Em um primeiro grande esforço sobre este tema, durante meu doutoramento - A Dramaturgia musical de Ésquilo - eu havia chegado ao limite da aplicação de uma abordagem estritamente textualista ${ }^{10}$. Os dados encontrados e novas discussões bibliográficas apontavam para a amplitude dos conceitos e das experiências descritas na tese.

\section{O PROJETO DE AGORA (2010-2011)}

No atual protótipo construído tal passagem da geração de dados para sua melhor organização recepcional se verifica na distribuição de telas, de modo que a organização visual acaba sendo uma análise do produto. Esse procedimento, ausente em pesquisas anteriores, demonstra a correlação em textualidades com orientação audiovisual e sua mediação tecnológica. Ao fim, o design se torna um processo de clarificação do objeto, ou seja, se torna um objeto midiático mesmo que interpreta as referências de seu material base.

O protótipo se apresenta atualmente com algumas telas. Entre elas, temos três telas de abertura, que apresentam uma introdução da peça analisada para o usuário.

Nestas três telas iniciais, orientamos o usuário para um contexto da peça que será estudada em sua textualidade, reforçando informações como a macroestrutura, ou divisão de partes da peça, e, na última das três telas, as marcas rítmicas do trecho que será o foco das análises. Dentro da perspectiva adotada na pesquisa, não disponibilizamos o resumo do enredo ou alguma interpretação mais fechada que preconizasse uma prévia explicação dos conteúdos. Antes, com o uso dos recursos na página principal do protótipo, como veremos, a ênfase está na correlação entre as dimensões visuais e sonoras do texto, homólogas da amplitude audiovisual do espetáculo. É nisso que se baseia a pesquisa: na homologia entre procedimentos de descrição e o objeto de análise.

${ }^{10}$ Publicada em livro: Mota (2008). 
Como exemplo, eis a primeira tela de abertura:

\title{
"AS SUPLICANTES" ESQUILO
}

Apresentamos um projeto de software que busca, a partir do texto de

As Suplicantes, de Ésquilo, servir como um campo de

experimentaçōes a respeito da textualidade de obras

multidimensionais. No caso, temos uma integração de referências que

vão do texto original em grego, sua traduçăo, comentários linguísticos, análise métrica até arquivos sonoros e visuais.

A peça As suplicantes encena os eventos de um grupo de mulheres que chega a Argos após fuga. São 50 mulheres que buscam asilo e proteção, pois não querem casar obrigadas com seus primos. Elas vêm para Argos, e a peça se organiza nes se contato com o governante local. O espetácula assim se divide em suas partes:

- Pároda: entrada do coro (1-175), na qual temos a entrada das mulheres em cena, seguidas por seu pai Dânao. Elas adentram o espaço de cena, o qual se marca por imagens dos deuses e um altar. Depois dessa entrada em anapestos (1-39), as mulheres começam uma performance organizada, com movimentos determinados (39-175), que no texto é marcada por estrofes duplas (estrofe/antiestrofe). Cada dupla de estrofe repete um mesmo conjunto de configuraçăo metrica. Nestas estrofes duplas o coro apresenta paralelos míticos à sua situação de agora.

\author{
(1)
}

Após as telas de introdução, segue-se a página de trabalho ou tela principal, na qual o texto original dos versos iniciais de As suplicantes é submetido a uma análise plural.

Na tela principal ou de trabalho, temos três grandes áreas: à esquerda é exibido o texto em grego da peça, que será alvo de procedimentos diversos de análise; à direita, temos dois tipos de informações que serão acessadas quando se clicar no texto em grego à esquerda: 1- um comentário do conteúdo de cada verso, que busca explicitar aspectos relevantes da relação entre aquilo que é veiculado pelo agente coral e sua recepção pela audiência; 2- análise gramatical de cada palavra dos versos do texto; abaixo, temos uma partitura que apresenta o espectro do som, o som, a notação musical tradicional que se articula em dois sistemas - um para o registro dos tempos a partir das sílabas e outro para os acentos da palavras. Ainda, temos o arquivo sonoro correspondente a esta representação visual. 


\section{"AS SUPLICANTES" ESQUILO}

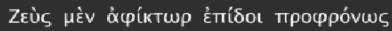

Comentários

Que Zeus protetor das suplicantes olhe com benevolência

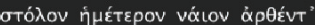

$u=u=-u u=$

para nosso grupo que desembarcou

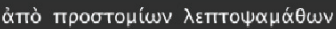

u u - u u - - u u -

vindo da foz de fina areia

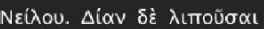

do Nilo. Deixando a terra de Zeus,

4

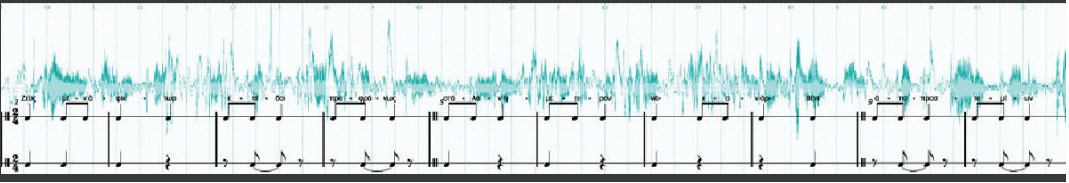

Detalhando uma análise, ou seja, clicando em um verso, temos a seguinte tela:

\section{"AS SUPLICANTES" ESQUILO}

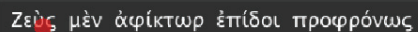

- u u - - u u - u u -

Que Zeus protetor das suplicantes olhe com benevolência

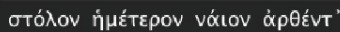

u $u-u$ u $-\mathrm{u} u$

para nos so grupo que desembarcou

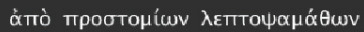

$\mathrm{u} u$ - u u $-\mathrm{u}_{\mathrm{u}}$

vindo da foz de fina areia

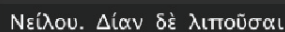

- $-\quad-\quad$ u $\mathrm{u}-{ }^{-}$
Comentários

Zeus é a primeira palavra da peça. A peça se inicia com um. súplica. Zeus, entre seus muitos atributos, é invocado con aquele que favorece o clamor dos que dele solicitam ajuda.

Analise gramatica

Zzus

Subs. Nam, s, masc.

Como se pode observar, o mouse está sobre a primeira palavra da peça (o nome do deus Zeus). Verticalmente, no lado esquerdo, vemos que abaixo da linha que apresenta a distribuição dos versos do texto em original, temos uma linha compostas pelos sinais métricos ( -UU...). Cada sílaba do texto original é transcrita em sua codificação métrica, informação que vai ser utilizada na elaboração da notação musical que se vê na parte baixa da página. Ainda, depois da linha com os sinais da transcrição métrica, temos a tra- 
dução em português especialmente elaborada por mim para este protótipo. Assim, cada verso na verdade se apresenta com um sistema de três linhas.

$\mathrm{Na}$ coluna da direita, a partir da palavra/verso marcado, temos as informações de conteúdo (comentário) e análise gramatical. Finalizando, a página principal, temos em sua parte de baixo a dimensão sonora da textualidade até aqui visualizada:

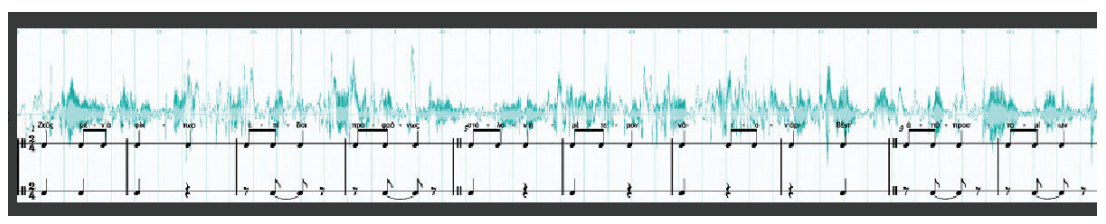

Nesta seção, quando acionado o botão de iniciar a reprodução do arquivo sonoro, temos uma linha do tempo, a sucessão linear que acompanha a sucessão das palavras do texto. Assim, o usuário vai ouvir o texto recitado no original e os sons da ordem dos textos marcados pelos sinais métricos e a ordem das intensidades marcada pelos acentos do texto.

Desse modo, o usuário possui a seu dispor diversos modos de concretizar uma experiência de fruição e análise da textualidade da tragédia. O usuário pode acessar dados isoladamente, como a informação gramatical ou comentário do verso escolhido, como pode também seguir o fluxo rítmico do verso em movimento em sua imagem na tela e simultaneamente na sucessão de seus sons percussivos e vocais correspondentes. Indo para o detalhe ou para o todo, o usuário experimenta os variados aspectos da definição multimodal dos textos da tragédia grega. E, em assim fazendo, o usuário pode ser coprodutor de sentido ao coperformar o texto a partir dos dados disponbibilizados.

\section{TEXTUALIDADES E MEDIAÇÕES TECNOLÓGICAS}

Uma filologia digital que integre a audiovisualidade registrada em documentos textuais do passado atualiza questões que problematizam a recepção dos textos considerados basilares para cultura ocidental e os métodos recursivamente utilizados para a continuidade de sua transmissão. 
Não é à toa que outras textualidades têm se valido da mediação tecnológica, acarretando processos comparativos que mutuamente se esclarecem. Cito dois exemplos: o do "Project Perseus", inspirador da interface aqui apresentada, e o "Learn Byzantine Chant"11.

A utilização de recursos baseados em novos modos de processamento de texto vem sendo uma constante em Estudos Clássicos desde os anos 80 do século passado ${ }^{12}$. As aplicações dessa revolução digital podem se ver principalmente na constituição de banco de textos online, com ferramentas complexas de buscas, como o Project Perseus, o TLG (Thesaurus Linguae Graecae) online e o Hodoi Elektronikai ${ }^{13}$. Milhares de pesquisadores e estudantes têm acesso a textos da antiguidade clássica gratuitamente, textos estes indexados a ferramentas de análise linguística (morfologia e sintaxe) e a comentários filológicos que englobam elucidações contextuais.

O exemplo mais bem sucedido dessa revolução digital se encontra no Project Perseus, que , a partir do banco de textos online, a biblioteca eletrônica iniciada em 1985, multiplicou seus campos de interesse e seus subprodutos. Sediado na Tufts University, o Project Perseus deixou de ser apenas um depositório de obras para se constituir em um centro multidisciplinar de pesquisas envolvendo textos, imagens e novas tecnologias e mesmo em objeto de investigação, em virtude de pioneirismo e know-how em hipertexto e hipermídia ${ }^{14}$.

${ }^{11}$ Links: perseus.tufts.edu ; chant.hchc.edu .

${ }_{12}$ Para uma visão dos principais sites,portais, centros de pesquisa e produtos v. www.tlg.uci. edu/index/resources. Neste portal, os links estão estão divididos e classificados em séries e tipos, além de virem seguidos de comentários. Para uma mapeamento das práticas, recursos e desafios das interfaces entre Estudos da Antiquidade e métodos de digitais de tratamento de dados consultar ] Bodard e Mahony (2010) e Donaati Giacomini (2002). Além disso, temos a revista Digital Humanities (www.digitalhumanities.org/dhq), que agrega um amplo espectro de pesquisas sobre o tema, consolidando o debate e discutindo metodologias em torno das relações entre e-science, artes e humanidades.

${ }_{13}$ Para acesso, v. Project Perseus www.perseus. tufts.edu ; TLG www.tlg.uci.edu ; e Hodoi Elektronikai www. mercure.fltr.ucl.ac.be/Hodoi.

${ }_{14}$ Para consulta da imensa bibliografia produzida a partir do Project Perseus, v. www.perseus.tufts.edu/hopper/about/publications. 
Ex. Página de abertura do portal Perseus Digital Library:

\section{PERSEUS DigITAL LIBRARY}

GREGORY R. CRANE, EDITOR-IN-CHIEF TUFTS UNIVERSITY

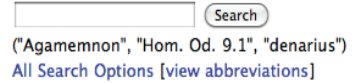

All Search Options [view abbreviations]

Home Collections/Texts Research Grants Open Source About Help

Welcome to Perseus 4.0, also known as the Perseus Hopper.

Read more on the Perseus version history.

New to Perseus? Click here for a short tutorial.

\section{Announcements}

- May 17, 2010:

- The Perseus website may be occasionally unavailable Saturday, May 22 and Sunday, May 23 due to hardware upgrades. We apologize for any inconvenience this may cause.

- February 5, 2010:

- We have fixed the problem with viewing full-size images in IE7 and 8 .

- February 4, 2010:

- A new release of our source code is now available on SourceForge. Updated data and text files are also available here.

- February 1, 2010:

- Become a fan of Perseus on Facebook!

- Problems viewing images on IE 7 and 8: We are aware of the problem with viewing full-size images through IE 7 or 8 and are working to fix it. For the best experience on Perseus, we always recommend using the latest version of Firefox.

- December 15, 2009:

- Updates to Perseus Digital Library: The Vocabulary Tool is now available. For more information about this tool, please see the help page.

- October 7, 2009:

- Updates to Perseus Digital Library: We have added many new authors and texts to our collection, including Seneca, Quintilian, Flaccus, Cicero, Aulus Gellius, Ammianus and Petronius.

Popular Texts

- Caesar, Gallic War (English, Latin)

- Catullus, Carmina (English, Latin)

- Cicero, In Catilinam I (English, Latin)

- Vergil, Aeneid (English, Latin)

- Herodotus, Histories (English, Greek)

- Homer, Odyssey (English, Greek)

- Plato, Republic (English, Greek)

- Tom Martin, Overview of Classical Greek

History from Mycenae to Alexander (English)

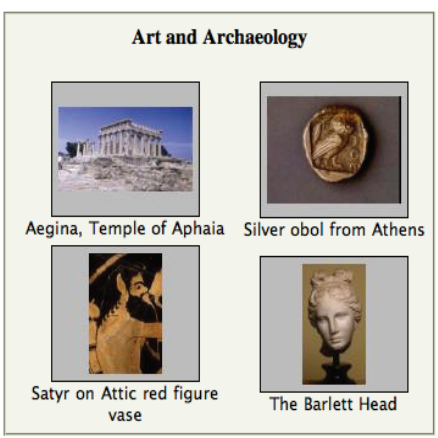

Exhibits

Hoje, além da consulta aos textos e seus hiperlinks, o Project Perseus disponibiliza imagens de objetos de arte, lugares e construções relacionadas à arte, literatura e cultura greco-latina; fontes textuais para estudo da cultura árabe, germânica e norte-americana. No caso dos textos greco-latinos, cada obra é apresentada em seu original, e dividida em suas tradicionais partes (no caso de uma tragédia temos prólogo, estásimos,episódios e êxodo). No alto da página há uma "linha do tempo", que situa o leitor no momento da peça que ele está lendo. No centro da página temos o texto principal. Clicando sobre cada palavra, são acessados links linguísticos e bibliografia secundária que remete o pesquisador a contextos e citações da palavra e/ou do verso escolhido, e dicionários que comentam o significado e uso dos vocábulos. Na lateral direita, um menu com várias opções é visivel: pode-se substituir 
o texto original por uma tradução, ou mesmo justapor na mesma página o original com uma ou mais traduções. Ainda, há mecanismos de busca que relacionam este texto lido com outros mais que o citam, ou ainda busca de outras palavras ou da mesma palavra na obra que está sendo examinada.

Ex. Página inicial de As Suplicantes, no Project Perseus.

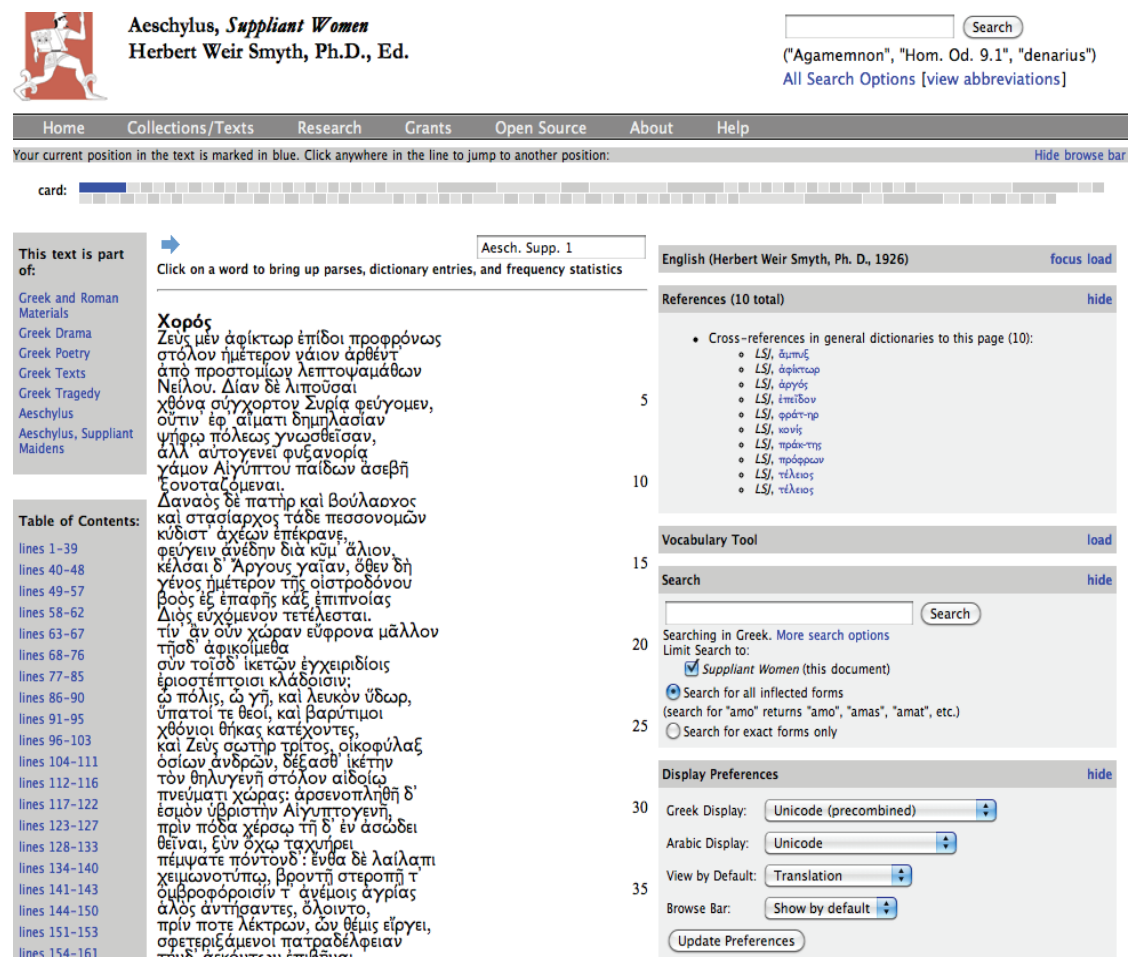

O modelo do Project Perseus é enciclopédico, pois faculta ao usuário uma plataforma multitarefa com acesso simultâneo a vários arquivos. $\mathrm{O}$ ponto de partida e alvo primordial é a palavra, mas há a possibilidade de outras 'janelas' que complementam a leitura e compreensão do texto.

No caso da pesquisa aqui proposta, em razão da especificidade dos textos teatrais, de sua textualidade espetacular, haveria de se trabalhar com outro 
modelo, que leve em consideração tanto a materialidade verbal da obra, quanto a materialidade de suas condições de performance ${ }^{15}$.

Em razão disso, à revolução digital nos Estudos da Antiguidade correlacionamos o performative turn nas Ciências Humanas e, especialmente, na compreensão de obras dramáticas greco-latinas ${ }^{16}$. Para tanto, os atuais recursos do Project Perseus seriam enriquecidos por outros que mais enfatizam a efetiva audiovisualidade do evento cênico, em parte registrada nos textos originais, em parte disponível em fontes extratextuais e nos cruzamento de informações. Em nossa proposta, o texto teatral seria o ponto de partida de outras formas de geração de referências e modos de se interrogar a teatralidade emergente a partir do estudo e análises da dimensão material da performance.

Dessa maneira, além de um depositário de dados, temos outras instâncias metacríticas, como se pode observar no esquema abaixo:

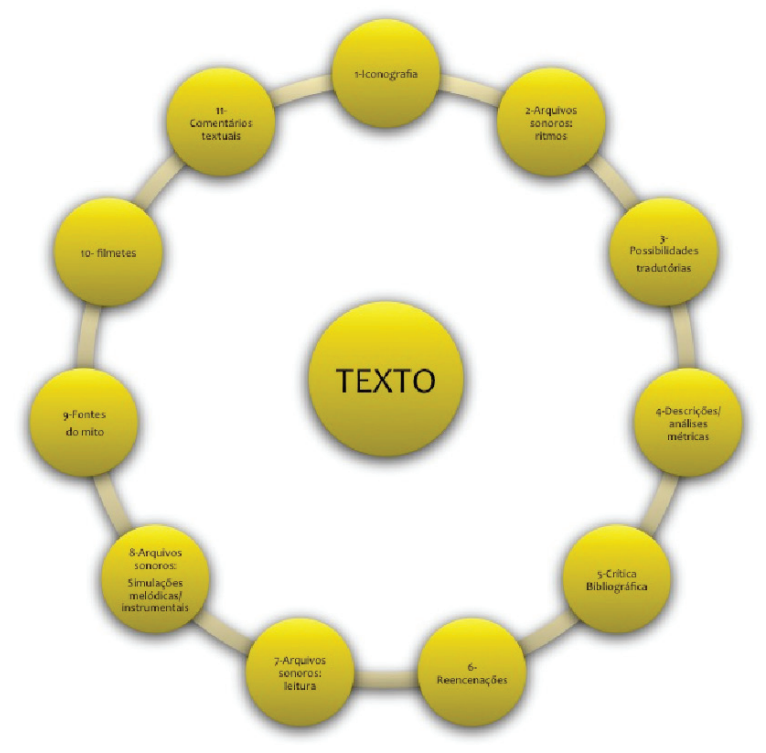

${ }^{15}$ Para o conceito de 'texto espetacular', v. Pavis (2005). Para a relação entre materialidade verbal e condições de performance v. Ley (2007); Wiles (2000)

${ }_{16}$ Para o conceito de 'performative turn' v. Carlson (1996); Schechner (2006); Bial, 2007; Fischer-Lichte (2008). 
Além de todos os versos dos textos com hiperlinks para explicações linguísticas, temos, tomando por exemplo a peça As suplicantes, de Ésquilo:

1. ICONOGRAFIA: imagens de vasos gregos, esculturas e pinturas antigas e pós-clásssicas que se relacionam o mito das Danaiades;

2. ARQUIVOS SONOROS.RITMOS: Interpretações em arquivos midi de trechos das partes cantadas e das partes faladas da peça;

3. POSSIBILIDADES TRADUTÓRIAS: Discussão de alternativas às atualizações linguísticas do texto, enfatizando as opções tradutórias, as equivalências ou não entre o texto grego e as novas interpretações;

4. DESCRIÇÕES/ANÁLISES MÉTRICAS: Interpretação métrica de todos os versos da peça;

5. CRÍTICA BIBLIOGRÁFICA: Comentário de artigos e obras que estudam diversos aspectos da peça;

6. REENCENAÇÕES: Apresentação de montagens da peça, com imagens e textos elucidativos;

7. ARQUIVOS SONOROS: LEITURA. Arquivos em wave com a reprodução vocalizada dos texto em grego e na tradução para o português;

8. ARQUIVOS SONOROS: SIMULAÇÕES MÉLODICAS/INSTRUMENTAIS: Arquivos midi que apresentam intepretação dos métrica do texto;

9. FONTES DO MITO: Tradução e comentários de principais textos que na antiquidade se apropriam e transforma o mito das Danaiades;

10. FILMETES: Trechos da peça filmados e disponibilizados.

11. COMENTÁRIOS TEXTUAIS: Explicações de partes obscuras do texto e de referências a eventos extratextuais presentes na peça, a partir da de As Suplicantes.

Quanto ao "Learn Byzantity Chant", a comparação com o protótipo aqui apresentado é enriquecedora.

$\mathrm{Na}$ tela de abertura, temos um cadastro que situa o usuário na relação com os níveis de utilização do material com o qual irá interagir: 


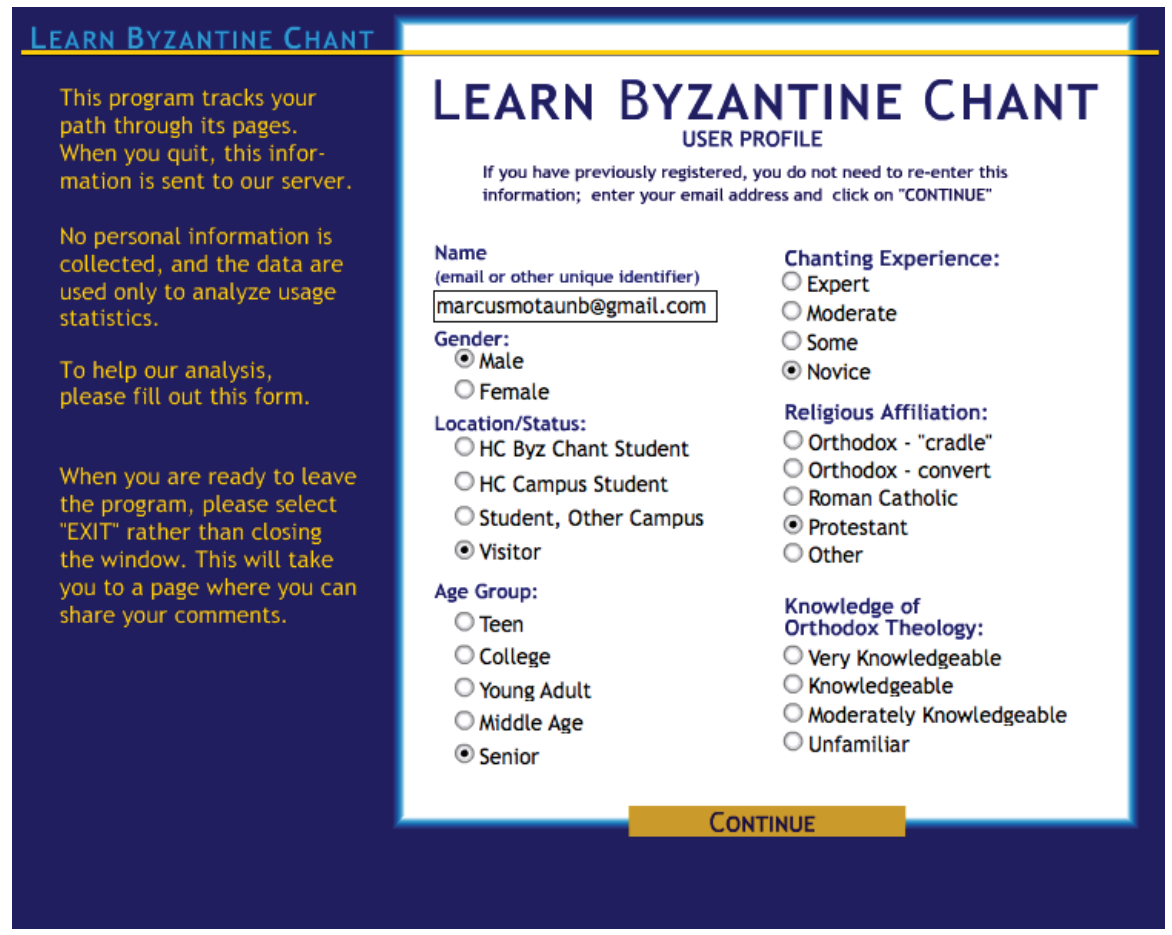

Em seguida, temos uma tela que oferece uma lista de possíveis itens com os quais o usuário vai interagir. Trata-se de um repertório de canções a partir do calendário de festividades religiosas.

Escolhida uma das canções, o usuário agora está diante da tela de trabalho ou principal, na qual várias possibilidades são oferecidas em função da canção de festa: 


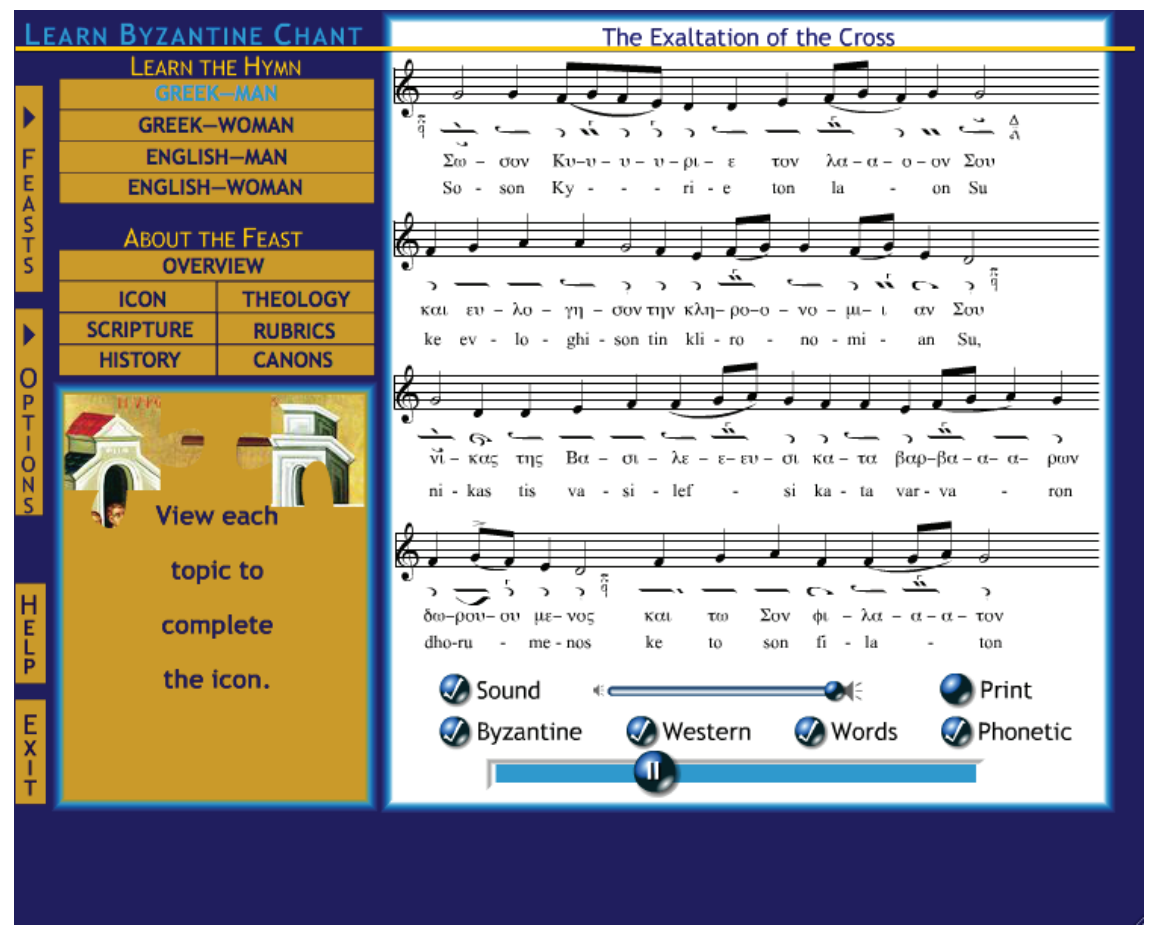

No canto de cima, o usuário situa o papel que quer adotar- homem/ mulher, grego/estadunidense. Escolhendo este papel, são alterados o texto da canção, a tessitura vocal e a melodia. A questão de gênero é aqui determinante.

A parte principal da tela apresenta a canção simultaneamente em: 1- notação musical tradicional; 2- notação bizantina; 3- texto em grego; 4- texto em grego transliterado. Ainda nessa parte principal, embaixo, o usuário tem as opções de visuação e audição do material: só ver a canção, mutando o som do arquivo da monodia vocal ou apenas uma das informações disponibilizadas (notação,texto); e pode imprimir a canção, com ou não a notação/texto.

Voltando para a coluna da esquerda, no icon "about the feast", o usuário possui uma verdadeira enciclopédia sobre cada uma das festas/canções, com textos imagens, comentários, discussões teológicas, tudo para subsidiar a compreensão e performance da obra. 
Na coluna da esquerda, vemos que o usário tem a opção de voltar para os menus anteriores.

Como se pode observar, há algumas coisas comuns entre o protótipo deste projeto desenvolvido no Laboratório de Dramaturgia e o Learn Byzantine Chant. A tela principal de trabalho centra-se no texto em suas dimensões visuais e aurais. As opções procuram satisfazer os vários graus de conhecimento da matéria. Pois, para quem desconhece notação musical ou para quem é iniciado na notação bizantina, haverá a opção de focar naquilo que busca visualizar. Ainda, a canção pode ser auralmente fruida ao mesmo tempo em que o texto é visualidado.

Por outro lado, frente às diferencas, a opção de se imprimir o material é uma possibilidade que pode ser incorporado em nosso protótipo. Daí a ênfase em um e outro procedimento. A longa enciclopédia correlata à canção manifesta os contextos de louvor, de orientação da participação da música na teologia. Em nosso caso, o objetivo dos comentários e notas gramaticas é subsidiar futuros empreendimentos e não suprir o usuário com o que ele deve fazer.

De qualquer forma, é digno de nota a correspodência entre textualidades que se definem por sua audiovisualidade.

\section{REFERÊNCIAS BIBLIOGRÁFICAS}

ADORNO, T.W.; EISLER, H. Composing for the Films. London: New York: International Publishing Group, 2007.

BIAL, H. (Org.) Performance Studies Reader. New York: Routledge, 2007.

BLASSINGHA, E. Perspectives: Creating and Producing Contemporary Opera and Musical Theater. Opera America, 1983.

BODARD, G.; MAHONY, S. Digital Research in the Study of Classical Antiquity. Burlington: Ashgate, 2010. 
BRACEWELL, J. L. Sound Design in the Theatre. Upper Saddle River (USA): Prentice Hall College Division, 1993.

CARLSON, M. Performance. A Critical Introduction. New York: Routledge, 1996.

CARTER, T. Monteverdi's Musical Theater. New Haven, Connecticut: Yale University Press, 2002.

COOK, N. Analysing Musical Multimedia. Oxford: New York: Oxford University Press, 2001.

DONATI GIACOMINI, P. Innovazione e tradizione: Le risorsse telematiche e informatiche nello studio della storia antica. Bolonha: Il Mulino, 2002.

EWANS, M. Wagner and Aeschylus. The Ring and the Oresteia. London: Faber and Faber, 1982.

FENEYROU, L. Musique et Dramaturgie. Paris: Publications de la Sorbonne, 2003.

FISCHER-LICHTE, E. The Transformative Power of Performance: A New Aesthetics. London: Routledge, 2008.

GENTILI, B. Poetry and Its Public in Ancient Greece. Baltimore: Johns Hopkins University Press, 1988.

GOLDMAN, A; SPINCHORN, E. Wagner on Music and Drama. New York: E.P. Dutton,1964.

HEILE, B. Recent Approaches to Experimental Music Theatre and Contemporary Opera. Music \& Letters, vol 87, issue 1, 72-81, 2006. 
LEBRECHT, J.; KAYE, D. Sound and Music for the Theatre: The Art and Technique of Design. [London: New York]: Focal Press, 1999.

LEONARD, J. A. Theatre Sound. London: Routledge, 2001.

LEY,G. The Theatricality of Greek Tragedy. Chicago: University of Chicago Press, 2007.

McMILLIN,S. The Musical as Drama. Princeton: Princeton University Press, 2006;

MOTA, M.; SOARES, E. A dramaturgia musical de C. Monteverdi. In: Anais Congresso Iniciação Científica. Brasília: Editora UnB, 2001, p.251.

MOTA, Marcus. A Dramaturgia Musical de Ésquilo. Composição, realização e recepção de ficções audiovisuais. Brasilia: Editora UnB, 2008.

- Metro e representação: geração de arquivos sonoros e midi a partir de textos da tragédia grega. In: SIMPÓSIO DE COGNIÇÃO E ARTES MUSICAIS, 7, 254-266, 2011, Brasília.

MURRAY, P.; WILSON, P.(Org.). Music and the Muses: Culture of Mousikê in the Classical Athenian City. New York: Oxford University, 2004

NAGY, G. Pindar's Homer the Lyric Possession of An Epic Past. Baltimore: Johns Hopkins University Press, 1990.

NAGY, G. Poetry as Performance: Homer and Beyond. Cambridge: Cambridge University Press, 1996.

PALISCA, C. The Florentine Camerata. New Haven, Connecticut: Yale University Press, 1989. 
PAVIS, P. A análise dos espetáculos. São Paulo: Perspectiva, 2005.

PICKARD-CAMBRIGDGE, A.W. The Dramatic Festivals of Athens. London: Oxford University Press, 1968.

SCHECHNER, R. Performative Studies. An Introduction. London: Routledge, 2006.

SCOTT, W.C. Musical Design in Aeschylean Theater. Hanover: Darmouth College, 1984;

SCOTT,W.C. Musical Design in Sophoclean Theater. Lebanon: University Press of New England, 1996.

SHARON, A.W. Drama as Opera: The Musical Theater of Classical Athens. Tese (doutorado). Boston University, 1994.

WAGNER, R. Opera and Drama. Lincoln: University of Nebraska Press, 1995.

WEST, M.L . Greek Metre. Oxford: Oxford University Press, 1987.

WILES, D. Tragedy in Athens: Performance Space and Theatrical Meaning. Cambridge: Cambridge University Press, 1997.

WILES, D. Greek Theatre Performance. Cambridge: Cambridge University Press, 2000. 